\title{
Pediatric patients on renal replacement therapy: clinic, epidemiological, social and economic profile
}

\begin{abstract}
Introduction: Pediatric chronic kidney disease interferes with weight growth, psychosocial status, and also affects quality of life.

Objectives: To outline the clinical, epidemiological, social and economic profile of children and adolescents undergoing renal replacement therapy (RRT) at Santa Casa de Belo Horizonte, Minas Gerais - Brazil.

Methods: Observational and cross-sectional study. 82 children and adolescents from 0 to $17 \mathrm{yrs}$ of age who had undergone RRT with at least three months of registration were included. Patients who died in the first three months on RRT, acute patients, and those older then $18 \mathrm{yrs}$ were excluded. Anthropometric analysis was performed and qualitative variables were expressed in absolute frequencies and percentage.

Results: $63.5 \%$ were male; median age of $9.25 \mathrm{yrs}$ at the beginning of RRT. $57 \%$ were short, and the BMI was normal in $88 \%$. $82 \%$ were followed by nephrologists before RRT, $64.5 \%$ had residual diuresis. Hemodialysis was the main initial modality of RRT. Long-term double-lumen catheter was the most widely used vascular access. $85 \%$ of those who were at school age were attending school. Most patients lived in the countryside, used public transport, and had a low per capita income. SUS (Health Unic System) was the paying source and were registered at UBS (Basic Health Unity). The mother was the caregiver in $80.5 \%, 36.6 \%$ had glomerulopathy and $26.8 \%$ CAKUT uropathy. Sepsis was the main cause of death. 34 patients were transplanted.
\end{abstract}

Discussion and Conclusion: To know the clinical, epidemiological, social, and economic profile of pediatric patients in RRT is important in order to increase the chances of successful treatment and a better quality of life.

Keywords: chronic kidney disease, child, adolescent, renal replacement therapy, dialysis, quality of life

\author{
Volume 9 Issue I - 202I
}

Celina F Rezende,' Maria Goretti M G Penido, ${ }^{1,2}$ André S Alvarenga,' Mariângela L Cherchiglia, ${ }^{3}$ Viviane L Nery'

'Pediatric Nephrology Unit - Nephrology Center of Santa Casa de Belo Horizonte, Belo Horizonte, Minas Gerais, Brazil ${ }^{2}$ Federal University of Minas Gerais - Faculty of Medicine, Department of Pediatric, Pediatric Nephrology Unit, Belo Horizonte, Minas Gerais, Brazil

${ }^{3}$ Federal University of Minas Gerais, Faculty of Medicine, Department of Preventive and Social Medicine, Public Health Unit, Belo Horizonte, Minas Gerais, Brazil

Correspondence: Maria Goretti Moreira Guimarães Penido, Rua Tomé de Souza, I 292/I OI, Bairro Funcionários, Belo Horizonte, MG, Brasil, CEP: 30 I40 I3I, Fax 55 31 324I4466, Emailmariagorettipenid@yahoo.com.br

Received: January 19, 2021 | Published: February 15, 2021

\section{Introduction}

Chronic kidney disease (CKD) is a disease that affects both structure and renal function, with multiple causes and prognostic factors. The progressive decrease of the glomerular filtration rate (GFR) determines loss of regulatory functions, excretory functions and renal and endocrines functions, compromising all other organs of the body. ${ }^{1,2}$ Patients in advanced stages of CKD have reduced life expectancy, increased risk of cardiovascular disease, major dietary restriction, use of large numbers of medications, and dramatic worsening of quality of life. ${ }^{3}$ Mortality is influenced by individual factors such as age, primary cause of CKD, comorbidities, and factors related to the use of health services such as late referral, use of temporary vascular access, and hospitalizations. ${ }^{4}$ Studies indicate a significant increase in the number of pediatric patients with terminal chronic kidney disease (TCKD) worldwide, with an incidence of four to nine patients per million of the child population, depending on the countries evaluated. ${ }^{4,5}$ However, epidemiological data on the incidence and prevalence of CKD and TCKD in the pediatric population are underestimated. According to Acúrcio et al. ${ }^{5}$ if all cases are analyzed this incidence will be much higher. ${ }^{6}$ It is known that children and adolescents with CKD and TCKD need special care, considering that this population is in the fundamental period for physical and mental development. There is a significant impact on quality of life, selfimage, cognitive development and hope for survival. In this scope, it was realized the need to know this population well with the purpose to help them in their social and economic difficulties. Therefore, the objective of this study was to describe the pediatric population attended at the Pediatric Nephrology Unit of the Santa Casa de Belo Horizonte Nephrology Center, from 2008 to 2016, in order to know its clinical, epidemiological, social and economic profile.

\section{Patients and Methods}

\section{Study design}

A cross-sectional and observational study of children and adolescents diagnosed with TCKD in renal replacement therapy (RRT).

\section{Patients}

Were included 82 children and adolescents from 0 to 17 years and 11 months who started dialysis or were kidney transplanted at the Pediatric Nephrology Unit of the Santa Casa de Belo Horizonte Nephrology Center from 07/01/08 to $07 / 01 / 16$, with at least three consecutive months of records of procedures to enter the cohort. Children and adolescents who died in the first three months in RRT, those with acute renal injury, and those over 18 years old were excluded.

\section{Methods}

Data collection were made on the database of the Santa Casa de Belo Horizonte Nephrology Center and on the medical records. The variables collected were: sex, age at onset of RRT, patient's origin, 
per capita income, RRT paying source, modality of transport to the treatment center, registration in the basic reference health unit, main caregiver, regular attendance at school, modality of the first RRT, follow-up with a nephrologist for less than one year, modality of the first RRT performed by the patient, presence of residual diuresis at the beginning of RRT, type of vascular access at the beginning of hemodialysis (HD), etiology of the underlying disease and causes of deaths.

\section{Statistical analysis}

The information obtained were recorded in specific database (Windows Excel platform, 2010, Microsoft Corp, Redmont, USA). GraphPad Prism 7 for Windows, version 4.02 was used. The qualitative variables were expressed in absolute frequencies and percentage. Anthropometric analysis was performed to obtain the $\mathrm{Z}$ scores of the BMI by age (BMI/A) and height by age (H/A). ${ }^{7}$ The $\mathrm{Z}$ scores for height and BMI/A were obtained from the WHO reference curves. ${ }^{8}$

\section{Ethical aspects}

The study was approved by the Research Ethics Committee of Santa Casa de Belo Horizonte (number 1,769,535) and was conducted in accordance with the ethical standards established in the 1964 Declaration of Helsinki. No Informed Consent was required because the information was collected from the database.

\section{Results}

The clinical, epidemiological, social and economic characteristics of the patients are described in Table 1. The majority of children and adolescents $(82 \%)$ were incidents on RRT, which means that they did not come from another dialysis center. The mother was the main caregiver in most patients $(80.5 \%)$. Among all patients evaluated, 54 were school-age patients and $46(85 \%)$ reported attending school regularly. As demonstrated in Figure 1, primary glomeronephritis was the main underlying disease, followed by the Congenital Anomalies of the Kidney and the Urinary Tract (CAKUT). During the study period, nine patients died. The causes of death are described in Figure 2. The main cause was sepsis $(56.0 \%)$.

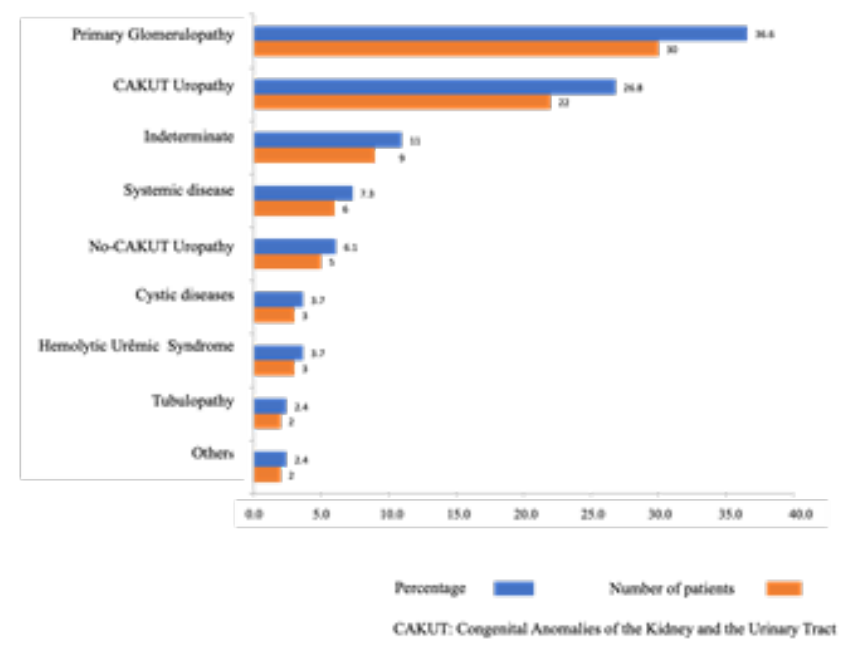

Figure I Etiology of patients' underlying disease.

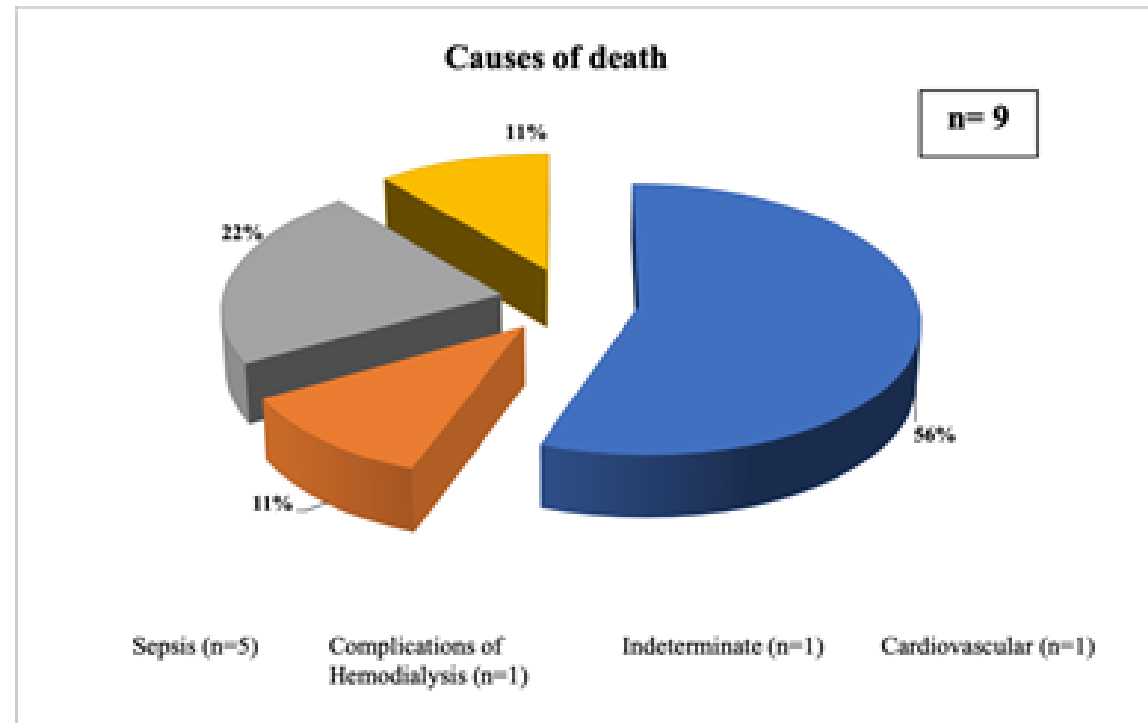

Figure 2 Causes of patients'death. 


\section{Discussion}

This study aimed to detail the clinical, epidemiological, social and economic profile of 82 children and adolescents in RRT monitored at the Pediatric Nephrology Unit of the Santa Casa de Belo Horizonte Nephrology Center. There was a predominance of males, which is in accordance with most studies described in the literature., ${ }^{4,-15}$ The median age of the patients was 9.25 years at onset on RRT. This finding is very close to those described in articles on RRT, in Serbia $^{11}$ which reported a median age of 9.8 years, in Korea ${ }^{12}$ where the median age was 9.7 years, and in Brazil ${ }^{14}$ which reported 12.5 years in a more recent study by Konstantyner et al. ${ }^{12}$ A median age of 13 years was found in India. ${ }^{16}$ It can be observed that the mentioned countries are developing countries. Reports from countries considered developed showed a lower median age of onset on RRT, as in Italy where the mean age was 6.9 years, and in Spain where the median was 3.9 years. ${ }^{4,5}$ This fact probably occurs because in these countries there is greater accessibility to diagnosis and because the main underlying diseases of renal failure in these pediatric populations are congenital abnormalities of the urinary tract and kidneys and hereditary diseases, which are diagnosed earlier (Table 1).

The growth of children and adolescents with CKD is often altered. Andrade and collaborators showed that patients with TCKD were significantly shorter than children and adolescents in the control group, in all age groups. However, when the weight to height ratio was evaluated, the $\mathrm{z}$ score averages were within the normal range. ${ }^{17}$ In the present study, the anthropometric data of 67 patients were evaluated, as there was no record of the others. At the beginning of the RRT it was identified that $48 \%$ of the patients were in -3 height/age ratio $\mathrm{z}$ score. However, the BMI $\mathrm{z}$ score was within the normal range in most of them, because they had low height and low weight. Thus, BMI would not be a good marker for nutrition in this group of patients (Table 1). There is evidence that delayed growth is highly prevalent at the beginning of dialysis treatment, as demonstrated by NAPRTCS 2011 and 2014. ${ }^{18,19}$ Some modifiable risk factors contribute greatly to this growth deficit, such as inadequate calorie and protein intake, especially in infants with severe CKD, in whom the height loss can be greater than 2 standard deviations in the first six months of life. Disorders in the growth hormone - insulin growth factor-1 (IGF-1) axis also contribute to the genesis of reduced growth in pediatric CKD (Table 1). ${ }^{20}$ Most patients (82\%) were followed-up by a nephrologist for at least one year when they started RRT, and this was scheduled. This may be a study bias, considering that the Pediatric Nephrology Unit of the Santa Casa de Belo Horizonte Nephrology Center is a reference in the Minas Gerais State and there is a specific outpatient clinic for patients with CKD under conservative treatment (Table 1).

Bastos \& Kirsztajn reported that early referral of adult patients with CKD to the nephrologist would be the ideal conduct. ${ }^{21}$ Roubicek et $\mathrm{al}^{21}$ observed that patients referred late were more likely to die in the first year of RRT onset. ${ }^{22}$ These findings emphasize the importance of remembering and encouraging other health professionals, who take care of patients at risk for CKD, to refer them for follow-up with a nephrologist and a specialized staff at an early stage. (Table 1). Residual diuresis was present in $64.5 \%$ of patients. The preservation of residual renal function is associated with better survival, lower morbidity and higher quality of life. Studies suggest that residual renal function seems to be particularly important for children on dialysis and was associated with better nutritional status, growth, cardiovascular function and survival (Table 1). ${ }^{23}$ Fifty-eight patients started dialysis with HD. According to Chesnaye et al. ${ }^{23} \mathrm{HD}$ was the first choice for pediatric patients in Canada and the United States, and
PD was the first choice in most European countries, New Zealand and Australia. ${ }^{10,24}$ The long-term double lumen catheter was the vascular access used by $48 \%$ of patients. In 2015 , Shin et al described this same finding. ${ }^{12}$ The lower proportion of arteriovenous fistula in pediatric patients is related to pain during sequential puncture, to limb positioning during HD and to the aim of transplanting children and adolescents as soon as possible (Table 1).

Table I Clinical and epidemiological characteristics of patients

\begin{tabular}{|c|c|}
\hline Characteristics & $n=82(100 \%)$ \\
\hline Males & $52(65.3 \%)$ \\
\hline Age at onset of RRT (median) & 9.25 years \\
\hline $0<2$ years & $13(16 \%)$ \\
\hline$>2<12$ years & $4 I(50 \%)$ \\
\hline$>12<18$ years & $28(34 \%)$ \\
\hline Short stature for age & $47(57 \%)$ \\
\hline Normal BMI & $72(88 \%)$ \\
\hline \multicolumn{2}{|l|}{ Follow-up with nephrologist } \\
\hline Yes & $67(82 \%)$ \\
\hline No & $5(6 \%)$ \\
\hline No data & $10(12 \%)$ \\
\hline \multicolumn{2}{|c|}{ Residual diuresis present at the beginning of RRT } \\
\hline Present & $53(64.5 \%)$ \\
\hline Absent & $15(18.5 \%)$ \\
\hline No data & $14(17 \%)$ \\
\hline Modality of the first RRT - Hemodialysis & $58(70.5 \%)$ \\
\hline Type of vascular access at the beginning of RRT & $58(100 \%)$ \\
\hline Native vein AVF & $15(26 \%)$ \\
\hline AVF prosthesis & $\mathrm{I}(2 \%)$ \\
\hline Double Lumen Catheter - short term & $14(24 \%)$ \\
\hline Double Lumen Catheter - long term & $28(48 \%)$ \\
\hline School-age patient & $54(100 \%)$ \\
\hline Attending school & $46(85 \%)$ \\
\hline Do not attending school & $7(13 \%)$ \\
\hline No data & I (2\%) \\
\hline
\end{tabular}

RRT, renal replacement therapy; BMI, body mass index; HD, hemodialysis; AVF, arteriovenous fistula

It was observed that 54 patients were of school agepatients and 46 attended school regularly. However, this is not the reality in most pediatric dialysis units, because most patients have indisposition after treatment, making school attendance difficult. Laplane and collaborators conducted a study with the purpose of creating activities to provide pediatric patients in HD with new knowledge and greater interaction among themselves. The authors obtained good results (Table 1). ${ }^{25}$ A significant number of patients (69.5\%) did not live in Belo Horizonte and in its environs. The majority of them used the city hall vehicles $(60 \%)$ to move from their residence to the dialysis center. This is extremely important and the guarantee of patient transportation in our country is due to Ordinance No. 55 (1999) of the Ministry of Health (Table 2) ${ }^{26}$ The analysis of socioeconomic data showed that most patients were of low income and that they needed the public 
health system. The majority of the families attended had per capita income equal to or less than a minimum wage, and $95 \%$ of the patients received their treatment through the Health Unic System (SUS Sistema Único de Saúde), which aims to provide universal access to the services, coordinate and expand coverage to more complex levels of care, and implement health promotion and disease prevention actions (Table 2). ${ }^{6,14,27}$ It is known that in developing countries, such as India, which does not have a health system like the SUS, the low-income population does not get adequate treatment (Table 2). ${ }^{16}$ Seventy-seven patients were registered in the Basic Health Units of their regions, where they got drugs and other inputs. This logistical support is very important for proper treatment. In developing countries that do not have an organized health system, patients in RRT have no subsidy for this treatment (Table 2). ${ }^{16}$

Table 2 Social and economic characteristics of patients

\begin{tabular}{|c|c|}
\hline Characteristics & $\mathrm{n}=82(100 \%$ \\
\hline \multicolumn{2}{|l|}{ Region of residence } \\
\hline $\mathrm{BH}$ and countryside & 57 (69.5\%) \\
\hline Other regions & 25 (30.5\%) \\
\hline \multicolumn{2}{|l|}{ Transport to the Treatment Center } \\
\hline Own transportation & II (I3.5\%) \\
\hline City hall transportation & 49 (60\%) \\
\hline Free pass & $19(23 \%)$ \\
\hline No data & $3(3.5 \%)$ \\
\hline \multicolumn{2}{|l|}{ Per capita income } \\
\hline Without income & $3(3.5 \%)$ \\
\hline$<$ I Minimum wage & $70(85.5 \%)$ \\
\hline$>1<5$ Minimum wage & 7 (8.5\%) \\
\hline >5 Minimum wage & $2(2.5 \%)$ \\
\hline \multicolumn{2}{|l|}{ RRT paying source } \\
\hline SUS & 78 (95\%) \\
\hline Health insurance & $4(5 \%)$ \\
\hline \multicolumn{2}{|l|}{ Patient registered at UBS } \\
\hline Yes & 77 (94\%) \\
\hline No & $2(2.5 \%)$ \\
\hline No data & $3(3.5 \%)$ \\
\hline \multicolumn{2}{|l|}{ Caregiver } \\
\hline Mother & $66(80.5 \%)$ \\
\hline Father & $6(7.5 \%)$ \\
\hline Others & 7 (8.5\%) \\
\hline No data & $3(3.5 \%)$ \\
\hline
\end{tabular}

$\mathrm{BH}$, belo horizonte; RRT, renal replacement therapy; SUS, sistema único de saúde - health unic system; UBS, unidade básica de saúde = basic health unit

The mother was the main caregiver of the patients $(80.5 \%)$ and this brings important repercussion in the family structure. According to Abrahão and collaborators, there are changes in the daily life of the family such as social, physical, and school and work limitations. Frequently, the adjustments in the physical structure of the house are necessary. ${ }^{28}$ This mother becomes so involved in her son's disease, leading to mother-child agglutination, and forgets herself. ${ }^{28}$ The fact that the mother is the main caregiver can be reinforced because we are in a patriarchal society (Table 2). Primary glomerulopathies was the main cause of TCKD (36.6\%). This finding is in line with those found by Youssef \& Abdelfatah in 2013 (35.5\%) in Egypt. ${ }^{29}$ Shin et $\mathrm{a}^{29}$ found that half of their patients had chronic glomerulopathies and the other half CAKUT uropathy as the cause of TCKD. ${ }^{12}$ Orr et al (2009) found 32.5\% glomerulopathies, 35.8\% CAKUT, and $31.7 \%$ cystic deseases and others as causes of TCKD ${ }^{10}$ Most studies show that CAKUT uropathy is the most common cause of TCKD in pediatrics. ${ }^{4,11,14}$ In the American USRDS registry, congenital diseases (CAKUT and hereditary nephropathies) were the most common causes of TCKD in younger children, while the proportion of acquired diseases progressively increased with the age.$^{30} \mathrm{~A}$ possible explanation for primary glomerulopathies as the first cause of TCKD in this study could be the fact that the loss of renal function in this disease occurs slowly and progressively, reaching failure at a later age, and most patients were schoolchildren and adolescents. Differently, congenital CAKUT-like diseases manifest early, leading the patient faster to complete loss of renal function. CAKUT uropathy was found in $26.8 \%$ and was the second cause of TCKD. Perhaps the lower number of CAKUT uropathy found in this study is a result of the difficulty of diagnosis and referral to a specialized center at the appropriate time (Figure 1). During the study period nine patients in dialysis treatment died and the main cause was sepsis (Figure 2). The patients who died had less RRT time ( $\mathrm{p}=0.023)$ and were significantly younger than the others $(\mathrm{p}=0.0006)$. These data are in accordance with those described in Europe by Chesnaey and collaborators. ${ }^{24}$ Thirty-four patients $(41.5 \%)$ were transplanted during the same study period. Two of them underwent preemptive transplantation from living donors and 32 received grafts from deceased donors. The survival rate of all patients, regardless of RRT modality, was $80.6 \%$ at the end of the study.

\section{Final considerations and conclusions}

The growing number of pediatric patients with CKD and the need for adequacy and improvement in therapeutic quality have been a huge challenge for nephrology teams. During the study period there has been a significant increase in the number of patients on RRT in this Pediatric Nephrology Unit, which is in congruence with the national and international literature. It can be concluded that the profile of the patients in the referred Unit was a small boy, in HD therapy, over 7 years old, non-resident in the city where he was receiving the treatment, cared for by his mother, with per capita family income less than a minimum wage, regularly attending school, enrolled in UBS, and receiving RRT and government transportation for his treatment. It is known that socioeconomic data of pediatric patients on RRT are scarce in literature, demonstrating that attention is directed to the clinical profile of the disease. The individual is fragmented and dissociated from the environment where he lives and from his economic conditions. The interdisciplinary team's work is important and aims a differentiated approach of this individual, understanding his singularities, as a biopsychosocial human being. The collaborative relationship created by the interdisciplinary staff between the medical team and the family helps greatly in the development of therapeutic plans that are more adapted to the needs and possibilities of the individual, in adherence to treatment and in psychosocial support. This action increases the chances of better treatment results and better quality of life. The present study presented limitations that should be highlighted. Among the weaknesses, perhaps the most important is the underreporting of patient data as occurred in the anthropometric evaluation that was found in only 67 patients. Others limitations were inadequate referral to pediatric nephrology services, loss of 
patients during follow-up, and the fact that these patients may not be representative of the general population. The strong point of the study is its representativeness, since it was carried out in an entirely public hospital, that only take care of patients from the public health network. These results could contribute to the design of political and clinical strategies for this socially vulnerable population.

\section{Acknowledgements}

We appreciate the special collaboration of all children, adolescents and their families. Without this contribution this study would not be possible.

\section{Conflcits of interest}

The authors declare there is no conflcit of interest.

\section{References}

1. Yang CW, Harris DCH, Luyckx VA, et al. Global case studies for chronic kidney disease/end-stage kidney disease care. Kidney Inter Supp. 2020;10:e24-e48.

2. Dienemann T, Fujii N, Orlandi P, et al. International Network of Chronic Kidney Disease cohort studies (iNET-CKD): a global Inetwork of chronic kidney disease cohorts. BMC Nephrol. 2016;17:121-30.

3. Bersan SAL, Amaral CFS, Gomes IC, et al. Letalidade e internações de pacientes em hemodiálise em plano de saúde. Rev Saúde Publica. 2013;47(3):624-33.

4. Ardissino G, Dacco V, Testa S, Bonaudo R, et al. Epidemiology of chronic renal failure in children: data from the ItalKid project. Pediatrics. 2003;111(4 Pt 1):e382-e387.

5. Areses Trapote R, Sanahuja Ibáñez MJ, Navarro M. Epidemiology of chronic kidney disease in Spanish pediatric population. REPIR II Project. Nefrologia. 2010;30(5):508-517.

6. Acúrcio FDA, Queiroz OV De, Machado EL. Perfil epidemiológico dos pacientes em terapia renal substitutiva no Brasil, 2000-2004 Epidemiological profile of patients on renal replacement therapy in Brazil. Rev Saúde Pública. 2010;44(4):639-49.

7. Brasil. Ministério da Saúde. Orientações para a coleta e análise de dados antropométricos em serviços de saúde: Norma Técnica do Sistema de Vigilância Alimentar e Nutricional - SISVAN / Ministério da Saúde, Secretaria de Atenção à Saúde, Departamento de Atenção Básica. Secretaria de Atenção à Saúde. Departamento de atenção Básica. 2011. p. 76.

8. World Health Organization, United Nations Childrens Fund. WHO child growth standards and the identification of severe acute malnutrition in infants and children. World Heal Organ. 2009. p. 11.

9. Warady BA, Chadha V. Chronic kidney disease in children: The global perspective. Pediatr Nephrol. 2007;22(12):1999-2009.

10. Orr NIT, McDonald SP, McTaggart S, et al. Frequency, etiology and treatment of childhood end-stage kidney disease in Australia and New Zealand. Pediatr Nephrol. 2009;24(9):1719-26.

11. Peco-Antic A, Bogdanovic R, Paripovic D, et al. Epidemiology of chronic kidney disease in children in Serbia. Nephrol Dial Transplant. 2012;27(5):1978-84.
12. Shin HS, Oh JY, Park SJ, et al. Outcomes of hemodialysis in children: A 35-year experience at severance hospital. Yonsei Med J. 2015;56(4):1007-14.

13. Kari JA, Desoky SME, et al. Predictors of renal replacement therapy and mortality in children with chronic kidney disease. Saudi Med J. 2015;36(1):32-39.

14. Konstantyner T, Sesso R, De Camargo MF, et al. Pediatric chronic dialysis in Brazil: Epidemiology and regional inequalities. PLoS One. $2015 ; 10(8): 1-15$.

15. Tan SY, Naing L, Han A, et al. Chronic kidney disease in children and adolescent in Brunei Darussalam. World J Nephrol. 2016;5(2):213-219.

16. Gulati S, Mittal S, Sharma RK, Gupta A. Etiology and outcome of chronic renal failure in Indian children. Pediatr Nephrol. 1999;13(7):594-596.

17. Andrade ZM, Carvalhaes JTA. Avaliação de déficit de estatura de crianças e de adolescentes com insuficiência renal crônica: Estudo comparativo com irmãos sem insuficiência renal. J Bras Nefrol. 2004;26(1):19-27.

18. North American Pediatric Renal Trials and Cooperative Studies (NAPRTCS) 2011 annual dialysis report. Emmes, 2011. p. 1-74.

19. North American Pediatric Renal Trials and Cooperative Studies (NAPRTCS) 2014 annual transplant report. Emmes, 2011.

20. Mehls O, Lindberg A, Haffner D et al. Long-term growth hormone treatment in short children with CKD does not accelerate decline of renal function: results from the KIGS registry \& ESCAPE trial. Pediatr Nephrol. 2015; 30:2145-2151.

21. Bastos MG, Kirsztajn GM. Chronic kidney disease: importance of early diagnosis, immediate referral and structured interdisciplinary approach to improve outcomes in patients not yet on dialysis. Bras $J$ Nefrol. 2011;33(1):93-108.

22. Roubicek C, Brunet P, Huiart L, et al. Timing of nephrology referral: influence on mortality and morbidity. Am J Kidney Dis. 2000; 36:35-41.

23. Il-Soo Ha, Hui K Yap, Reyner L Munarriz, et al. Risk factors for loss of residual renal function in children treated with chronic peritoneal dialysis. Kidney Int. 2015;88(3):605-13.

24. Chesnaye N, Bonthuis M, Schaefer F, et al. Demographics of paediatric renal replacement therapy in Europe: a report of the ESPN/ERA-EDTA registry. Pediatr Nephrol. 2014;29(12):2403-2410.

25. Laplane ALF, Jajbhay SF, Frederico JCC. Crianças com doença renal crônica não estudam? Crit Educ. 2015;1(2447-4223):218-229.

26. Portaria n 55 (1999) do Ministério da Saúde. 1999.

27. Paim J, Travassos C, Almeida C, et al. The Brazilian health system: History, advances, and challenges. Lancet. 2011;377(9779):1778-97.

28. Abrahão SS, Ricas J, Andrade DF, et al. Dificuldades vivenciadas pela família e pela criança/adolescente com doença renal crônica. $J$ Bras Nefrol. 2010;18-22.

29. Youssef DM, Neemat-Allah MAA. Hemodialysis in children: Eleven years in a single center in Egypt. Iran J Kidney Dis. 2013;7(6):468-74.

30. Collins AJ, Foley RN, Herzog C, et al. US renal data system 2010 annual data report. Am J Kidney Dis. 2011;57(Suppl 1):A8 e1-526. 